\title{
The aldosterone receptor antagonist spironolactone prevents peritoneal inflammation and fibrosis
}

\author{
Lei Zhang ${ }^{1}$, Jian-Bing Hao', Lian-Sheng Ren', Jiu-Li Ding² and Li-Rong Hao
}

Peritoneal fibrosis is a complication of patients with long-term continuous ambulatory peritoneal dialysis (CAPD). Reports have indicated that angiotensin (Ang) II may correlate with the development of peritoneal fibrosis. However, it is unknown whether aldosterone also has a role in the development of peritoneal inflammation and fibrosis. The aim of the present study was to clarify the role of aldosterone in peritoneal inflammation and fibrosis. A rat model of peritoneal inflammation and fibrosis was established by daily intraperitoneal injection of dialysates and lipopolysaccharide in a 4-day interval over a period of 7 days. The animals were randomly assigned to five groups as follows: control (C); peritoneal dialysis (PD); peritoneal dialysis-spironolactone (PD-S); peritoneal dialysis-cilazapril (PD-C); and peritoneal dialysisspironolactone-cilazapril (PD-SC). After 30 days, the TGF- $\beta 1$ concentration in dialysates from all treatment groups was determined by ELISA. The histopathology of the parietal peritoneum was examined, and the expression of MCP-1, C-Jun, fibronectin (FN) and TGF- $\beta 1$ in the abdominal membrane was determined by immunohistochemistry. Mineralocorticoid receptor (MR), 11 $\beta$-hydroxysteroid dehydrogenase type 2 (11 $\beta$-HSD2) and CYP11B2 (aldosterone synthase) were analyzed by real time-PCR. Collagen deposition was significantly higher in PD compared with the other groups. The expression of MR, 11 $\beta$-HSD2 and CYP11B2 was significantly higher in PD compared with the other groups. Spironolactone and/or cilazapril treatment partially ablated the increase in monocyte chemoattractant protein (MCP)-1, p-c-Jun, transforming growth factor (TGF)- $\beta 1, \mathrm{FN}, \mathrm{MR}, 11 \beta$-HSD2 and CYP11B2. Furthermore, treatment with spironolactone and/or cilazapril also reduced the infiltration of CD-4- and ED-1-positive cells in rat peritoneal tissues after peritoneal fibrosis. Exogenous aldosterone may have a key role in the development of peritoneal inflammation and fibrosis. Spironolactone decreased peritoneal inflammation and fibrosis, which was associated with reduced secretion from peritoneal macrophages, inactivation of the c-Jun N-terminal kinase (JNK) pathway and subsequent downregulation of the expression of TGF- $\beta 1$. Laboratory Investigation (2014) 94, 839-850; doi:10.1038/labinvest.2014.69; published online 26 May 2014

KEYWORDS: aldosterone; c-Jun; MCP-1; peritoneal fibrosis; TGF- $\beta 1$

Peritoneal dialysis $(\mathrm{PD})$ is an attractive treatment for patients with end-stage kidney disease. However, long-term PD is associated with the development of functional and structural alterations of the peritoneal membrane. ${ }^{1}$ Several factors are thought to be involved in the development of peritoneal fibrosis in PD patients. Inflammatory cytokines in the peritoneal cavity during peritonitis may also trigger chronic inflammation and fibrosis.

A number of studies have now shown that macrophages have an important role in many aspects of tissue injury, inflammation and repair. ${ }^{2,3}$ Macrophages can be activated via a number of intracellular signaling pathways (ie, c-Jun amino terminal kinase (JNK), p38 mitogen-activated protein kinase (FcR/Syk), Janus kinase/signal transducer and activator of transcription (JAK/STAT)).

TGF- $\beta 1$ has a pivotal role in peritoneal fibrosis. ${ }^{4}$ During long-term CAPD, the concentrations of TGF- $\beta$ in PD effluents are significantly elevated, particularly in patients with peritonitis. ${ }^{5}$ TGF- $\beta 1$ drives the peritoneal deterioration induced by dialysis fluid and highlights the role of TGF- $\beta 1$ mediated mesothelial-to-mesenchymal transition in the pathophysiology of peritoneal-membrane dysfunction. ${ }^{6}$

JNK is a member of a larger group of Ser/Thr protein kinases known as the mitogen activated protein kinase

\footnotetext{
${ }^{1}$ The Second Ward of the Department of Nephrology, First Affiliated Hospital of Harbin Medical University, Harbin, China and ${ }^{2}$ Hospital of Hei Long Jiang Province, Harbin, China

Correspondence: Professor L-R Hao, PhD, MD, The Second Ward of the Department of Nephrology, First Affiliated Hospital of Harbin Medical University, 23 Youzheng Street, Nangang District, Harbin, Heilongjiang 150001, China.

E-mail: haolirong97566@126.com

Received 1 October 2013; revised 31 March 2014; accepted 21 April 2014
} 
(MAPK) family, which can be activated by TGF- $\beta$ through TGF- $\beta$-activated kinase $1 .^{7,8}$ Recent work identified JNK1 as a crucial mediator of TGF- $\beta 1$-induced epithelial-mesenchymal transition $(\mathrm{EMT})^{9}$ and lung fibrosis. ${ }^{10}$

Several lines of evidence suggest that the reninangiotensin-aldosterone system may have a key role in the development of tissue fibrosis. Ang II promotes the expression of MCP- 1 and TGF- $\beta 1$, which ultimately leads to deposition in the extracellular matrix. ${ }^{1-14}$ Although aldosterone promotes tissue fibrosis in many organs, its contribution to peritoneal fibrosis and the underlying mechanism are poorly understood. Aldosterone-induced TGF- $\beta 1$ expression in mesangial cells is regulated by the ERK1/2, JNK and AP-1 intracellular signaling pathways. ${ }^{15}$

In this study, we investigated the hypothesis that aldosterone could promote peritoneal inflammation and fibrosis by stimulating the secretion of macrophages in the peritoneum, activating the JNK pathway, and further upregulating the expression of TGF- $\beta 1$.

\section{MATERIALS AND METHODS}

\section{Animal Model And Treatment Groups}

We established a rat model of peritoneal inflammation and fibrosis as described by Nie et al. ${ }^{16}$ Fifty male Wistar rats, aged 6-8 weeks and $180-200 \mathrm{~g}$ in weight, were purchased from the Animal Laboratory Service (Harbin Medical University, China), and the experiments were conducted in accordance with animal care guidelines.

The rats were randomly assigned to five groups of 10 rats each: group I, control (C); group II, peritoneal dialysis (PD); group III, peritoneal dialysis-spironolactone (PD-S); group $\mathrm{IV}$, peritoneal dialysis-cilazapril ( $\mathrm{PD}-\mathrm{C})$; and group $\mathrm{V}$, peritoneal dialysis-spironolactone-cilazapril (PD-SC). Peritoneal inflammation was established in rats in the groups II-V by daily intraperitoneal injection of $4.25 \%$ glucose dialysates (Baxter Healthcare, Deerfield, Illinois, USA) at a dose of $100 \mathrm{ml} / \mathrm{kg}$ and lipopolysaccharide (Sigma, St Louis, Missouri, USA) at a dose of $0.6 \mathrm{mg} / \mathrm{kg}$ in a 4-day interval over a period of 7 days. Food and water were given ad libitum to all the groups. Rats in groups III-V received spironolactone (aldosterone receptor antagonist, $50 \mathrm{mg} / \mathrm{kg} / \mathrm{day}$ ), cilazapril (ACE inhibitor, $10 \mathrm{mg} / \mathrm{kg} /$ day) and spironolactone plus cilazapril, respectively. These medications were dissolved in drinking water immediately before administration by gastric gavage once daily in the morning.

\section{Peritoneal Equilibration Test (PET)}

Rats from all the treatment groups were euthanized on day 30 for baseline assessment of ultrafiltration and membrane transport. At $4 \mathrm{~h}$ after intraperitoneal infusion of $30 \mathrm{ml}$ of $4.25 \%$ Dianeal, animals were killed. An accurate ultrafiltration volume was measured, and blood samples were obtained. Automatic biochemistry analyzer was used to measure the creatinine in plasma $\left(\mathrm{P}_{\mathrm{cr}}\right)$ and final
PD effluent (D), the glucose in initial $\left(\mathrm{D}_{0}\right)$ and final PD effluent $\left(\mathrm{D}_{4}\right)$. The values of $\mathrm{D} / \mathrm{P}_{\mathrm{cr}}$ and $\mathrm{D}_{4} / \mathrm{D}_{0}$ were calculated.

\section{Experimental Procedures}

After 30 days of treatment, $10 \%$ chloral hydrate (an anesthetic, $3 \mathrm{ml} / \mathrm{kg}$ ) was injected intraperitoneally using a 22-gauge needle. Following a gentle abdominal massage, a tube was inserted into the peritoneal cavity through a midline incision. The peritoneal fluid was aspirated through a syringe without leakage. The aspirated peritoneal fluid was immediately centrifuged $\left(4^{\circ} \mathrm{C}, 4000\right.$ r.p.m. for $10 \mathrm{~min}$ ), and the supernatants were stored at $-70^{\circ} \mathrm{C}$ for double-blinded measurement of TGF- $\beta 1$ later. The rats were killed by hypovolemia, and together with the peritoneum, tissue samples were obtained from the abdominal wall away from the injection site. The tissue samples were stored at $-70^{\circ} \mathrm{C}$.

\section{Histological Tissue Analysis}

Tissue samples $(5 \times 2 \times 2)$ were then immersed in $10 \%$ formalin for $24 \mathrm{~h}$ and embedded in paraffin. Sections $(2 \mu \mathrm{m})$ were stained with hematoxylin and eosin (HE) and Masson's trichrome stain. For each section, 10 visual fields $(\times 200$ times) were observed. The presence of collagen was evaluated quantitatively from Masson's trichrome-stained sections using the HPIAS-1000 analytic software (Champion Image Engineering Company of Tongji Medical University, Wuhan, China). The thickness of the connective tissue between the mesothelium and the abdominal wall was evaluated using the HPIAS-1000 analytic software. Three random areas of each tissue section were measured, and three tissue sections per rat were examined.

\section{Measurements of TGF- $\beta 1$ in the Abdominal Cavity Liquid by ELISA}

The levels of activated TGF- $\beta 1$ in the abdominal cavity liquid under different experimental conditions were measured by ELISA kit for TGF- $\beta 1$ (R\&D Systems, USA) according to the manufacturer's protocol. The absorbance at $450 \mathrm{~nm}$ was measured by a microplate reader. The concentrations of activated TGF- $\beta 1$ were determined from the standard curve.

\section{Immunohistochemistry}

Immunohistochemical staining was performed using the streptavidin-biotin-peroxidase technique. Briefly, endogenous peroxidase activity was quenched in $0.3 \% \mathrm{H}_{2} \mathrm{O}_{2}$, and then nonspecific protein binding sites were blocked by incubating with $10 \%$ normal serum. MCP-1, p-c-Jun, TGF- $\beta 1$, $\mathrm{FN}$, macrophages and lymphocytes were stained with antiMCP-1, anti-p-c-Jun, anti-TGF- $\beta 1$, anti-FN (Santa Cruz Biotechnology, California, USA), anti-CD68 (Abcam, Cambridge, UK) and anti-CD4 (Abcam, Cambridge, UK) antibodies, respectively. Brown and yellow staining was 
considered positively stained. A total of 40 fields of the parietal peritoneum were observed blindly under magnification $(\times 200)$ as a semi-quantitative assessment. The MCP- $1, \mathrm{p}$-c-Jun, TGF- $\beta 1$ and FN staining in the parietal peritoneum field was evaluated by the HPIAS- 1000 analytic software. The positive signals were quantified as the optical density $(\mathrm{A}) \times$ positive area. The number of macrophages (ED1 + cells) and lymphocytes (CD4 + cells) were counted by the HPIAS-1000 analytic software.

\section{RNA Isolation and Real-Time PCR Analysis of MR, CYP11B2 and 11 $\beta$-HSD2 Expression Levels}

Total RNA was isolated from the abdominal membrane using the RNeasy Mini Kit (Qiagen, Valencia, CA) according to the manufacturer's protocol. Complementary DNA was generated using the Super-ScriptTM III First-Strand Synthesis System (Invitrogen). Real-time quantitative PCR was performed using the SYBR Premix Ex Taq (Takara Bio), and the Light Cycler 480 (Roche Diagnostics, Mannheim, Germany). The following primer sets were used to amplify: rat MR, forward primer: 5'-TTGGAGCGTTCTTCACTTG GAC-3' ${ }^{\prime}$, reverse primer: $5^{\prime}$-ATTGTCTTGCTGAATGTAAGG GAGT-3'; rat CYP11B2, forward primer: 5'-ATACCACAA TACTCCAGGAACAA- $3^{\prime}$, reverse primer: $5^{\prime}$-AGGCAGCATC ACAGACACAA- $3^{\prime}$; rat $11 \beta$-hydroxysteroid dehydrogenase type $2\left(11 \beta\right.$-HSD2) , forward primer: $5^{\prime}$-GAGAGGATGCTAC AGACCACTTC- $3^{\prime}$, reverse primer: $5^{\prime}$-TGCCAACAACCAGA CAAATACA- $3^{\prime}$; and rat $\beta$-actin, forward primer: $5^{\prime}$-TGGGT ATGGAATCCTGTGGCA- $3^{\prime}$, reverse primer: $5^{\prime}$-TGTTGGCA TAGAGGTCTTTACGG- $3^{\prime}$. The cDNA content of each specimen was determined using a comparative cycle threshold (CT) method with $2^{-\Delta \Delta \mathrm{CT}}$. To normalize the data, $\beta$-actin expression levels was used as an internal control.

\section{Statistical Analysis}

All obtained numerical data are expressed as mean \pm s.d. ANOVA was used to analyze groups with more than two sets of data, and Fisher's $D$ was used to compare groups of data. All statistical calculations were processed using the SPSS 11.0 software (SPSS, Chicago, Illinois, USA). $P$-values of $<0.05$ were considered statistically significant.

\section{RESULTS}

\section{Morphological Changes of the Peritoneum and} Peritoneal Function

Morphological changes of the peritoneum were evaluated by $\mathrm{HE}$ and Masson's trichrome. As shown in Figure 1, normal rat peritoneum was thin, consisting of a linear layer of mesothelial cells, and there were few inflammatory cells in the colic omentum. In the PD group, a loss of mesothelial cells and increased numbers of inflammatory cells in the colic omentum were evident at 4 weeks after initiation of PD.

As shown in Figure 2, compared with normal rats, severe peritoneal dysfunction demonstrated by a significant decrease in the peritoneal ultrafiltration and $\mathrm{D}_{4} / \mathrm{D}_{0}$ was found in the $\mathrm{PD}$ group. The $\mathrm{D} / \mathrm{P}_{\mathrm{cr}}$ in the $\mathrm{PD}$ group was significantly higher than those of rats in the control group $(P<0.01)$. In contrast, spironolactone or cilazapril (PD-S, PD-C and PD-SC groups) attenuated the changes $(P<0.01)$.

\section{MR, CYP11B2 and 11 $\beta$-HSD2 mRNA Expression in the Peritoneal Tissues}

CYP11B2 is a key factor in aldosterone synthesis. RT-PCR showed that the mRNA expression of CYP11B2 and MR in normal peritoneal tissues was minimal (Figure 3 ) but was substantially upregulated in the PD group $(P<0.01)$. In contrast, animals that received spironolactone or cilazapril treatment (PD-S, PD-C and PD-SC groups) showed a marked reduction in peritoneal MR and CYP11B2 mRNA $(P<0.01)$.

As the nonselective MR activation by glucocorticoids may also have a role in peritoneal fibrosis, we examined the mRNA expression of $11 \beta$-HSD2, an enzyme that protects against glucocorticoid-induced MR activation by converting biologically active 11-hydroxysteroid (cortisol) to the inactive 11 -ketosteroid form (cortisone). 11 $\beta$-HSD2 enzyme was absent in the peritoneum of the control group but was upregulated in the $\mathrm{PD}$ group $(P<0.01)$. Compared with the $\mathrm{PD}$ group, spironolactone or cilazapril (PD-S, PD-C and PD-SC groups) attenuated the changes $(P<0.01$; Figure 3$)$.

\section{Aldosterone Receptor Antagonism Reduced Inflammation and Fibrosis in the Peritoneum Peritoneal thickness and collagen fibers}

The normal rat peritoneum was thin and consisted of little collagen deposition as shown by Masson's trichrome staining (Figure 4). In the PD group, there was an increase in peritoneal thickness with richness of collagen matrix deposition in the submesothelial zone $(P<0.01)$. The thickness of the peritoneum and collagen matrix deposition in the spironolactone or cilazapril (PD-S, PD-C and PD-SC) groups were significantly different from that of the $\mathrm{PD}$ group $(P<0.01)$.

\section{FN and MCP-1 expression levels}

Deposition of FN and MCP-1 were increased in the PD group $(P<0.01$; Figures 5 and 6$)$. Treatment with spironolactone or cilazapril attenuated FN and MCP-1 deposition with weak staining of the mesothelial cells. Semi-quantitative analysis showed that the expression levels of MCP-1 and FN in spironolactone/cilazapril-treated rats (PD-S, PD-C and PDSC groups) were significantly lower than that in $\mathrm{PD}$ rats $(P<0.01)$.

Numbers of ED-1- and CD-4-positive cells

Immunohistochemistry showed that both ED-1- and CD-4-positive cells in the control group were minimal (Figure 7). A significant increase in the numbers of ED-1and CD-4-positive cells was observed in the $\mathrm{PD}$ group $(P<0.01)$; this increase was significantly inhibited by 

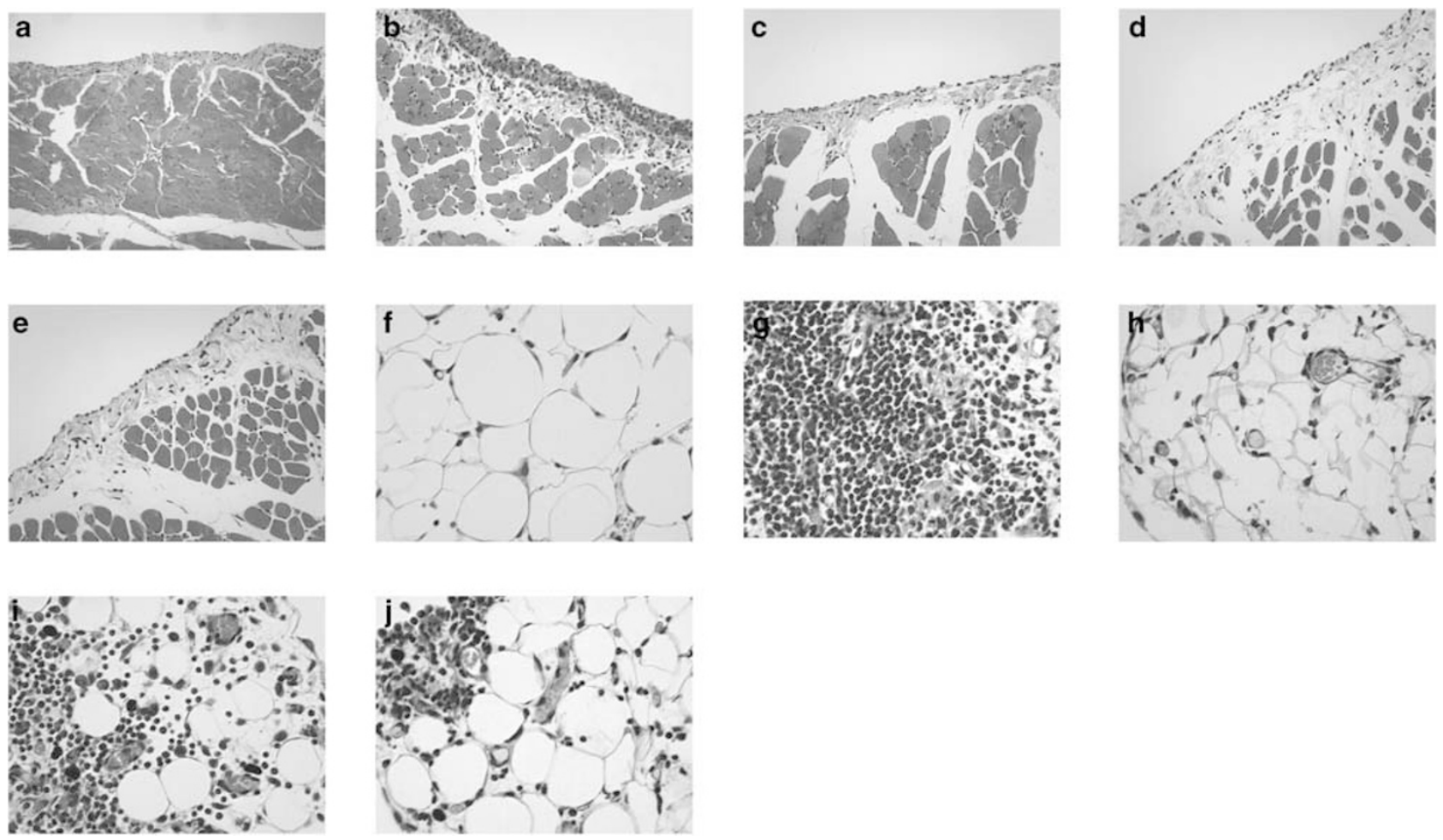

Figure 1 Histology of the peritoneum in all the groups after daily peritoneal dialysis for 30 days. In the control (a and f) group, few mesothelial cells and inflammatory cells in the peritoneum and colic omentum; in the peritoneal dialysis (b and $\mathbf{g}$ ) group, a loss of mesothelial cells in the peritoneum and a gain of inflammatory cells in the colic omentum; and in the peritoneal dialysis-spironolactone (c and $\mathbf{h}$ ), peritoneal dialysis-cilazapril (d and $\mathbf{i})$ or peritoneal dialysis-spironolactone-cilazapril (e and $\mathbf{j}$ ) groups, spironolactone or cilazapril prevents loss of mesothelial cells and inhibits inflammatory infiltrate. (a-e) Hematoxylin-eosin (HE) staining of the peritonium (original magnification $\times 200$ ); (f-j) hematoxylin-eosin (HE) staining of colic omentum (original magnification $\times 200$ ).
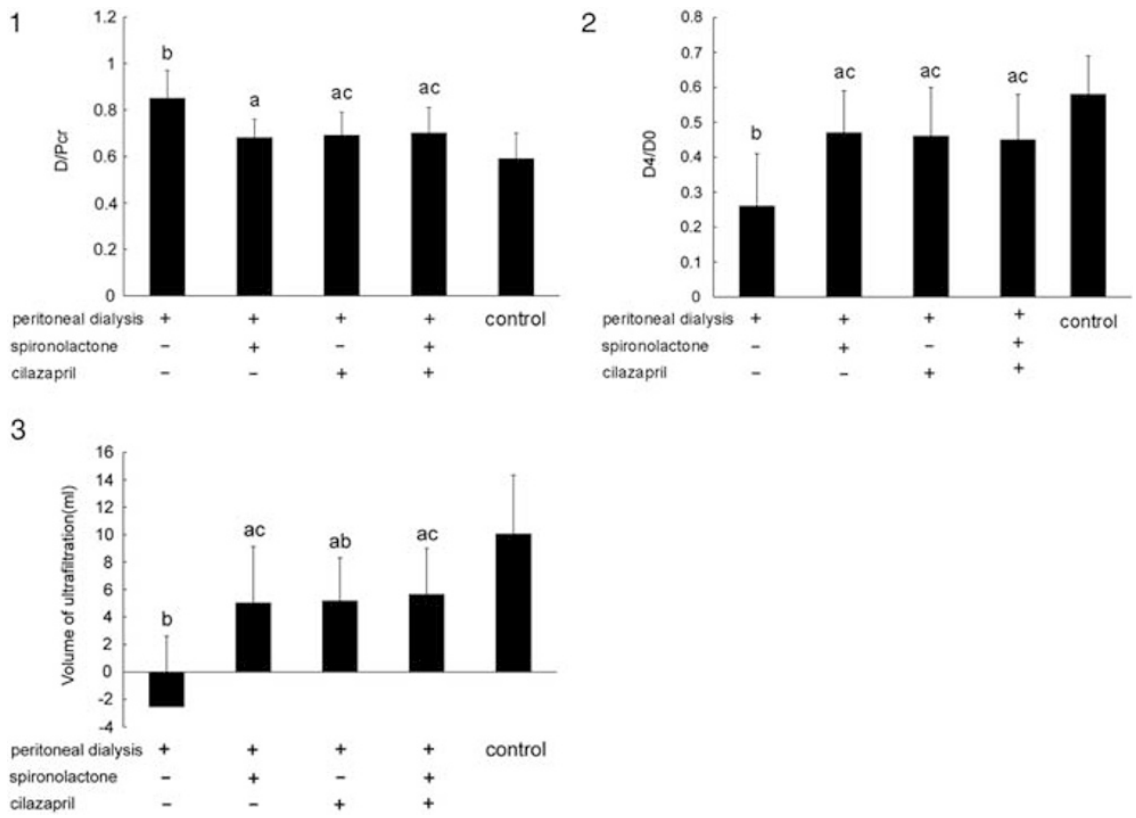

Figure 2 Peritoneal equilibration test was performed for $4 \mathrm{~h}$ at the end of the 30 days. The $D / P_{c r}$ level (1), the ratios of D4/D0 glucose level (2) and volume of ultrafiltration (3) were determined. The treatment of each group is indicated below the histogram. Each histogram represents mean \pm s.e.m. of 10 animals. ${ }^{a} P<0.01$ vs peritoneal dialysis (PD) group, ${ }^{b} P<0.01$ vs normal control group, ${ }^{c} P<0.05$ vs normal control group. 
spironolactone or cilazapril treatment (PD-S, PD-C and PD-SC groups). Quantitative analysis showed that both ED-1- and CD-4-positive cells in the peritoneal tissues of spironolactone/cilazapril-treated rats (PD-S, PD-C and PD-SC groups) were significantly lower than that in the PD group $(P<0.01)$.

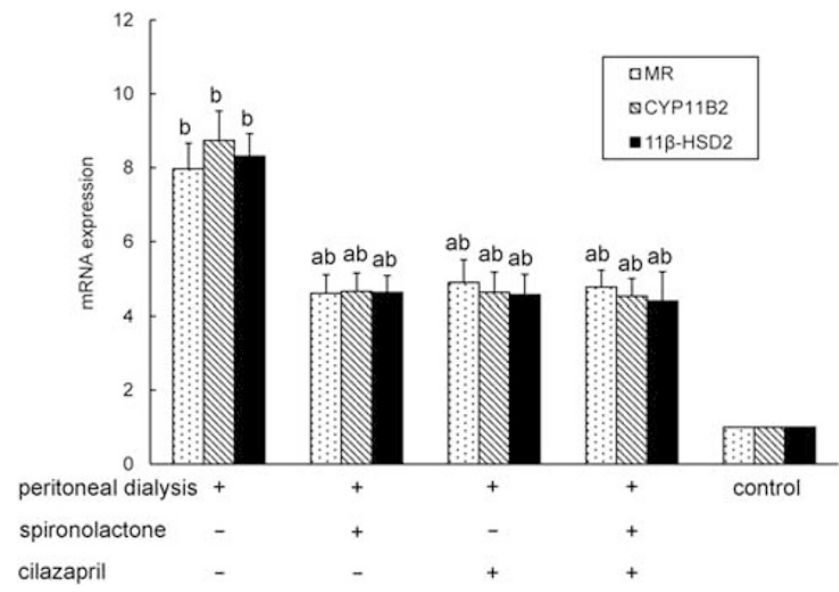

Figure 3 Expression of MR, CYP11B2 and 11 $\beta$-HSD2 mRNA in abdominal membrane. Each one of the five groups of 10 rats were dialyzed as described in Methods for 30 days. At the end of this period, the peritoneum was isolated and the mRNA levels for MR, CYP11B2 and $11 \beta$-HSD2 were determined by real-time PCR and normalized to $\beta$-actin. The control values are shown as 1.0. All values are presented as the mean \pm s.e.m. ${ }^{\mathrm{a}} P<0.01$ vs peritoneal dialysis (PD) group, ${ }^{\mathrm{b}} P<0.01$ vs normal control group.

\section{Inactivation of the c-Jun Pathway by Aldosterone Receptor Antagonism}

The expression of $\mathrm{p}$-c-Jun was weak in normal rats (Figure 8). The PD group exhibited greater p-c-Jun expression in the abdominal membrane $(P<0.01)$, whereas treatment with spironolactone or cilazapril (PD-S, PD-C and $\mathrm{PD}-\mathrm{SC}$ groups) showed reduced $\mathrm{p}$-c-Jun expression $(P<0.01)$.

\section{Aldosterone Receptor Antagonism Downregulates the Expression of TGF- $\beta 1$}

It is well known that TGF- $\beta 1$ have a critical role in the peritoneal structural alteration in PD. As shown in Figure 9(1), TGF- $\beta 1$ released into the abdominal cavity liquid was markedly increased in the PD group $(P<0.01)$ but was significantly inhibited by spironolactone or cilazapril $(P<0.01)$.

The peritoneum of normal rats had weak expression of TGF- $\beta 1$ (Figure 9(2)). No staining of peritoneal mesothelial cells was apparent in the control group. The rats from the PD group exhibited greater TGF- $\beta 1$ immunostaining in the abdominal membrane $(P<0.01)$, whereas treatment with spironolactone or cilazapril (PD-S, PD-C and PD-SC groups) was characterized by reduced TGF- $\beta 1$ immunostaining in the abdominal membrane $(P<0.01)$.

\section{DISCUSSION}

Peritoneal inflammation is an initial and essential step in the development of peritoneal complications associated with long-term PD. The peritoneum is infiltrated with white
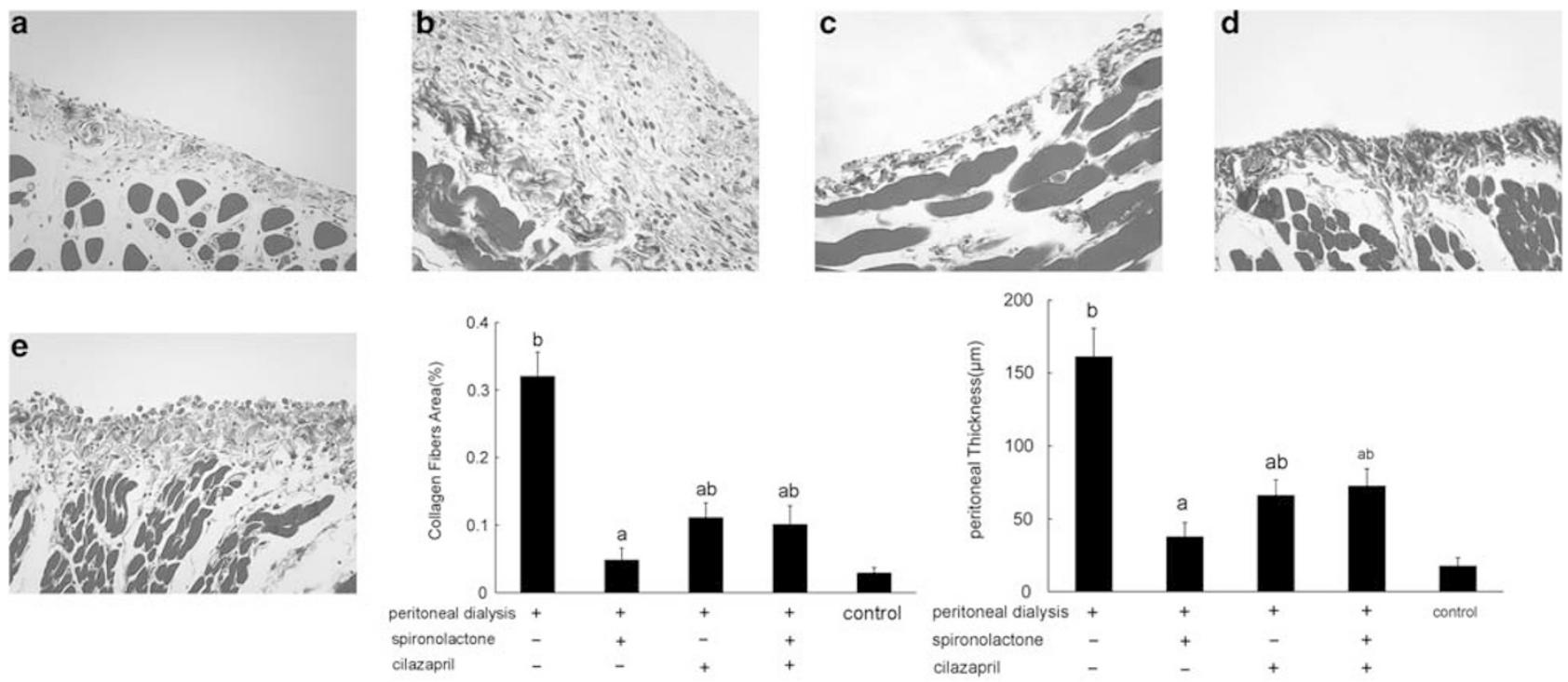

Figure 4 Aldosterone receptor antagonism reduced the peritoneal fibrosis after chronic peritoneal dialysis. Masson's trichrome-stained for mean peritoneal thickness and collagen (Original magnification $\times 200)(\mathbf{a}-\mathbf{e})$. In the control group $(\mathbf{a})$, peritoneum was thin; in the peritoneal dialysis

(b) group, an increase in peritoneal thickness with a richness of collagen matrix deposition was observed; and in the peritoneal dialysis-spironolactone (c), peritoneal dialysis-cilazapril (d) or peritoneal dialysis-spironolactone-cilazapril (e) groups, spironolactone or cilazapril recover the change. Each histogram represents mean \pm s.e.m. of 10 animals. ${ }^{\mathrm{a}} P<0.01$ vs peritoneal dialysis (PD) group, ${ }^{\mathrm{b}} P<0.01$ vs normal control group. 

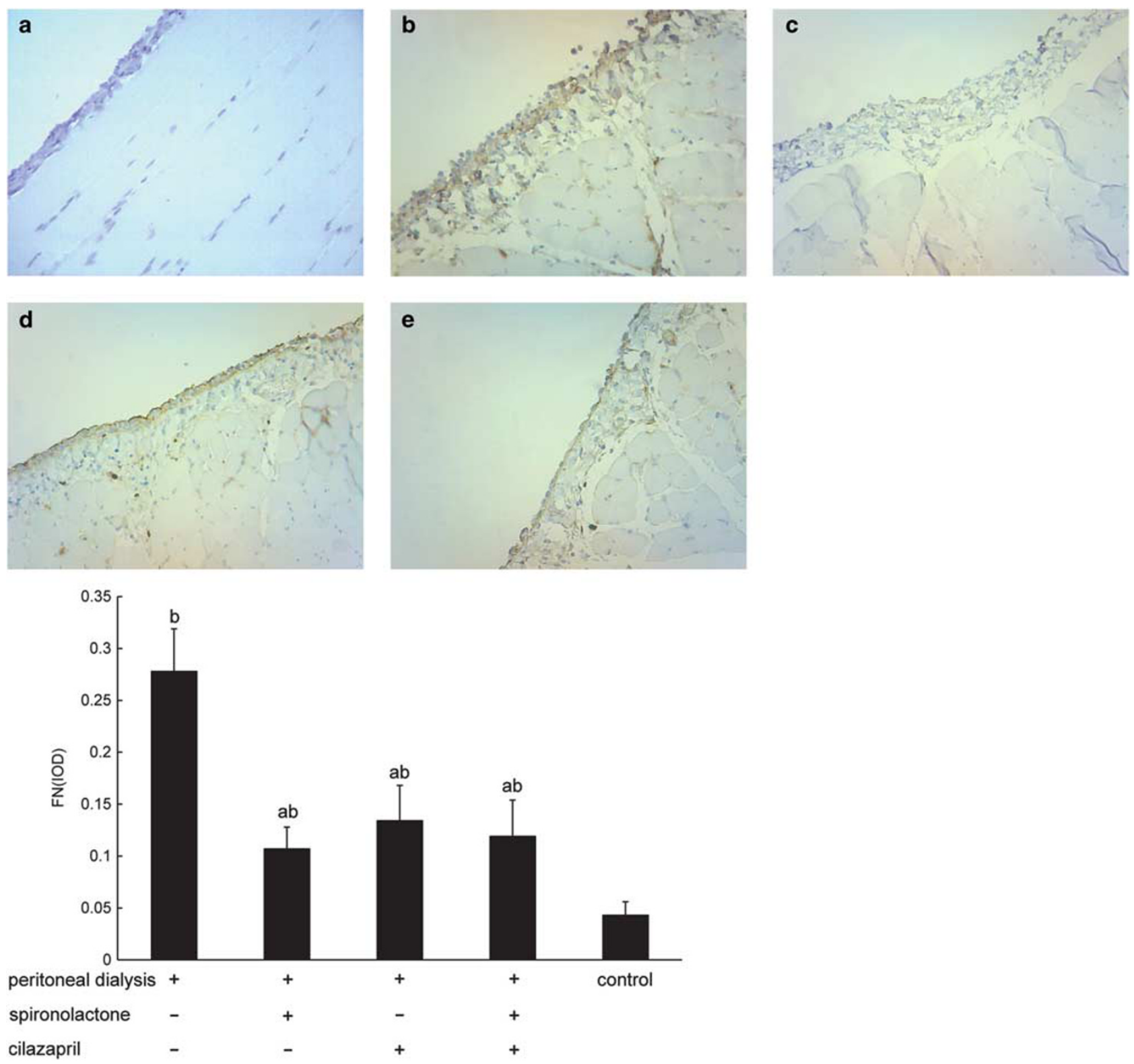

Figure 5 Aldosterone receptor antagonism decreased the FN in the peritoneum. Immunohistochemical staining for FN (brown, original magnification $\times 200)(\mathbf{a}-\mathbf{e})$. In the control group (a), deposition of FN were low; in the peritoneal dialysis (b) group, FN were increased; and in the peritoneal dialysisspironolactone (c), peritoneal dialysis-cilazapril (d) or peritoneal dialysis-spironolactone-cilazapril (e) groups, spironolactone or cilazapril recover the change. Each histogram represents mean \pm s.e.m. of 10 animals. ${ }^{a} P<0.01$ vs peritoneal dialysis (PD) group, ${ }^{b} P<0.01$ vs normal control group.

blood cells and macrophages, which can release high levels of free oxygen radicals, proteinases, prostaglandins, leukotrienes and cytokines, including TNF- $\alpha$, IL- $1 \beta$, MCP- 1 and RANTES. These substances are known to damage the structural integrity of the peritoneum by targeting peritoneal mesothelial cells, eventually resulting in fibrosis and loss of peritoneal function. ${ }^{17-21}$

A key role for macrophages in fibrosis has been observed in diverse organ settings. In PD patients, compared with uninfected patients, macrophages display an upregulation ex vivo. ${ }^{22}$ Some studies have shown that the macro- phages may participate in human peritoneal fibrosis through the stimulation of fibroblast cell growth and CCL18 production. ${ }^{23}$ Other research has indicated that macrophages may also have a crucial role in peritoneal fibrosis induced by high glucose and that the function of M2 macrophages in peritoneal fibrosis may be related to the TGF- $\beta /$ Smad signaling pathways. ${ }^{24}$ In our study, we found that the quantity of macrophage ED1 is increased in $\mathrm{PD}$ rats.

The function of JNK signaling is dependent on phosphorylation of activation domains (via upstream MKK4 or 

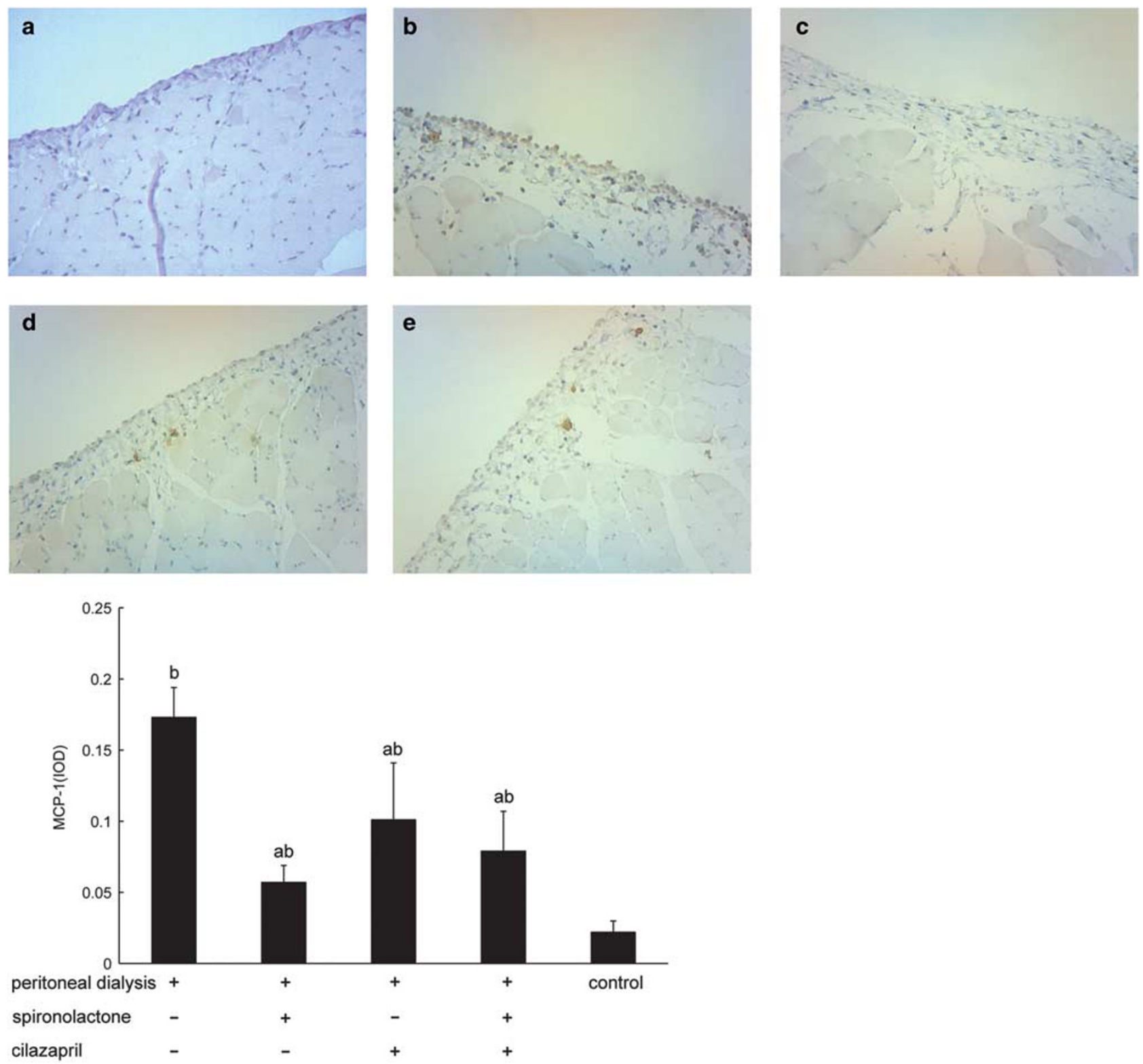

Figure 6 Aldosterone receptor antagonism reduced the expression of MCP-1 in the peritoneum. Immunohistochemical staining for MCP-1 (brown, original magnification $\times 200)(\mathbf{a}-\mathbf{e})$. In the control (a) group, deposition of MCP-1 were weak; in the peritoneal dialysis (b) group, MCP-1 were increased; and in the peritoneal dialysis-spironolactone (c), peritoneal dialysis-cilazapril (d) or peritoneal dialysis-spironolactone-cilazapril (e) groups, spironolactone or cilazapril recover the change. Each histogram represents mean \pm s.e.m. of 10 animals. ${ }^{a} P<0.01$ vs peritoneal dialysis group, ${ }^{\mathrm{b}} \mathrm{P}<0.01$ vs normal control group.

MKK7) that enables JNK to phosphorylate a range of target proteins that include transcription factors (ie, c-Jun, JunD, Smad3) and other signaling pathway elements that induce pro-inflammatory, pro-fibrotic and/or pro-apoptotic responses. ${ }^{25}$ JNK activation can be detected in infiltrating macrophages in experimental rat anti-glomerular basement membrane disease and in cisplatin-induced acute renal injury. ${ }^{26,27}$ Another study of human kidney disease has used immunodetection of c-Jun phosphorylation to identify JNK signaling in many glomerular and tubular cells, to the extent that tubulointerstitial JNK activation has been negatively correlated with estimated glomerular filtration rate. ${ }^{28}$ In our study, p-c-Jun showed higher expression levels in the PD group compared with reduced ex-pression levels in the other groups that were treated with spironolactone and/or cilazapril, indicating that JNK is activated in the PD group.

Recent studies have demonstrated evidence for crosstalk between the JNK and TGF- $\beta 1$ signaling pathway. For example TGF- $\beta 1$ can mediate the activation of JNK1. ${ }^{29,30}$ 

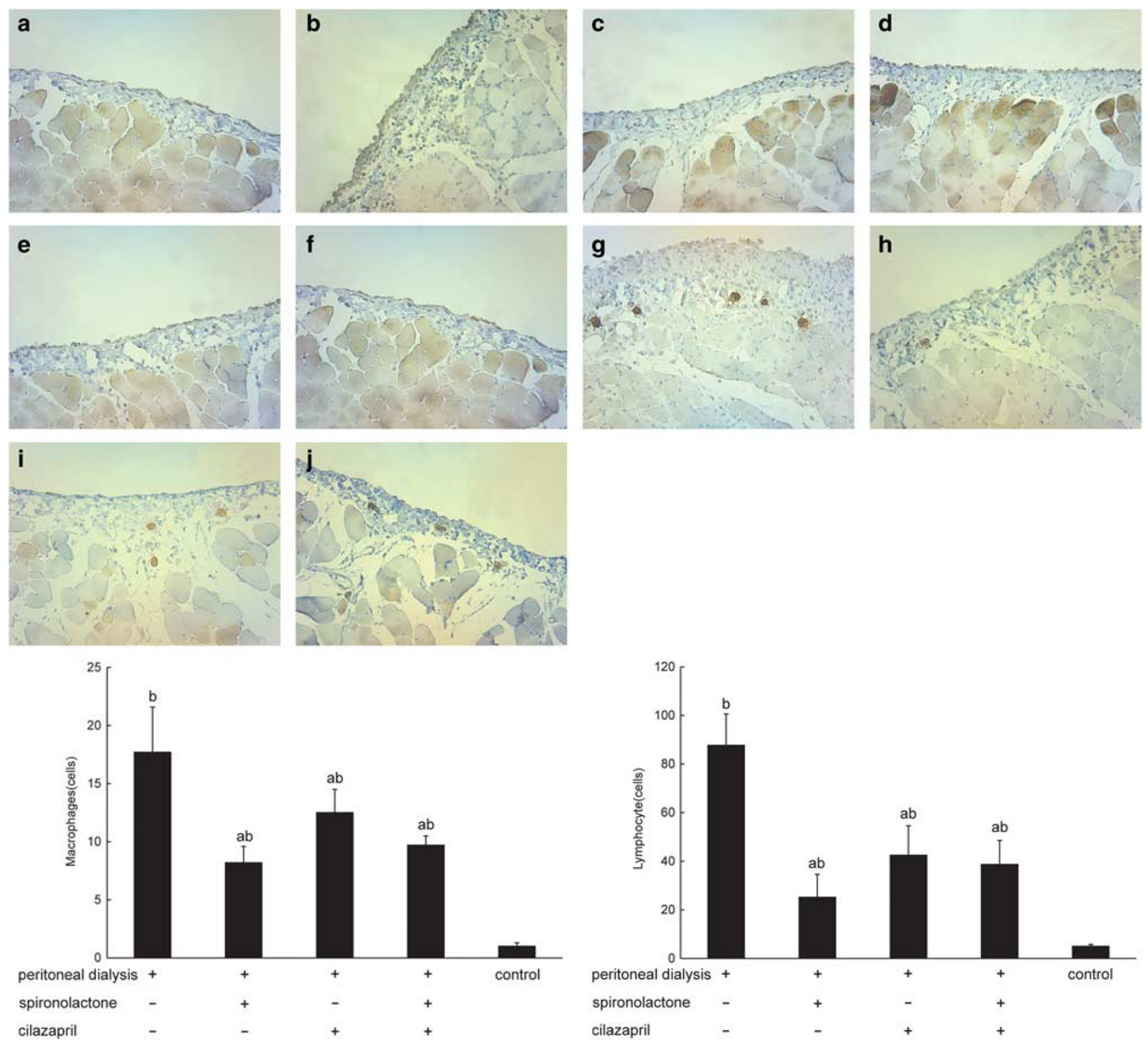

Figure 7 Aldosterone receptor antagonism decreased the inflammation after chronic peritoneal dialysis. Immunohistochemical staining for lymphocyte and macrophage infiltration. (a-e) Lymphocyte identified by immunohistochemical staining of CD4 (brown, original magnification $\times 200) ;(\mathbf{f}-\mathbf{j})$ ED1 + macrophages identified by immunohistochemical staining of CD68 (brown, original magnification $\times 200$ ). In the control group (a and f), CD-4- and ED-1-positive cells were minimal; in the peritoneal dialysis ( $\mathbf{b}$ and $\mathbf{g}$ ) group, the numbers of CD-4- and ED-1-positive cells increased; and in the peritoneal dialysis-spironolactone ( $\mathbf{c}$ and $\mathbf{h}$ ), peritoneal dialysis-cilazapril ( $\mathbf{d}$ and $\mathbf{i})$ or peritoneal dialysis-spironolactone-cilazapril (e and $\mathbf{j}$ ) groups, spironolactone or cilazapril recover the change. Each histogram represents mean \pm s.e.m. of 10 animals. ${ }^{a} P<0.01$ vs peritoneal dialysis (PD) group, ${ }^{\mathrm{b}} \mathrm{P}<0.01$ vs normal control group.

Furthermore, JNK-dependent phosphorylation of c-Jun and JunB has been demonstrated to mediate the antagonistic effects of inflammatory cytokines on TGF- $\beta 1 / \mathrm{Smad}$ signaling. ${ }^{30}$ In pulmonary fibrosis, studies have demonstrated the pivotal importance of the JNK1 signaling pathway in augmenting the expression of pro-fibrotic mediators and identified JNK1 as a crucial amplifier of TGF- $\beta 1$-induced EMT. 9,10

Aldosterone is a steroid hormone that acts via the mineralocorticoid receptor (MR). MR differs from the other steroid receptors in that it responds to two physiological ligands, aldosterone and cortisol. MR binds aldosterone and cortisol with equal affinity, but the presence of the cortisolinactivating enzyme $11 \beta$-HSD2 confers aldosterone specificity for MR in tissues where they are coexpressed..$^{31}$ Funder $^{32}$ recently suggested that $11-\beta \mathrm{HSD} 2$ may be important in aldosterone selectivity by inhibiting the ability of cortisol to act as an MR agonist rather than excluding cortisol from binding MR. In our study, MR is barely detectable, and $11 \beta$-HSD2 is absent in the normal peritoneum. However, 
MR and 11 $\beta$-HSD2 are upregulated in the peritoneum after inflammation and fibrosis. The parallel upregulation of $11 \beta$ HSD2 and MR suggests the potential for aldosterone-specific signaling within the fibrotic peritoneum.

MR is present in various nonepithelial cells, where aldosterone causes inflammation and fibrosis through genomic and nongenomic actions. ${ }^{33}$ We found that MR and CYP11B2 expression was enhanced in the peritoneum. CYP11B2 is a key factor in aldosterone synthesis. Macrophage MRs are necessary for the translation of inflammation and oxidative stress into interstitial and perivascular fibrosis after NO deficiency, even when plasma aldosterone is not elevated. ${ }^{34}$ Spironolactone prevented these changes, which might be a reason for the reduction of fibrosis.
Aldosterone has been reported to induce collagen synthesis in cultured cardiac fibrosis, ${ }^{35}$ vascular smooth muscle cells ${ }^{36}$ and glomerular mesangial cells. ${ }^{37} \mathrm{~A}$ number of studies have shown that spironolactone acts to prevent cardiac and renal fibrosis by inhibiting the synthesis of plasminogen activator inhibitor-1, TGF- $\beta 1$, MCP-1 and reactive oxygen species. $^{38,39}$ Irbesartan and spironolactone seem to decrease the extent of peritoneal injury caused by bacterial peritonitis. ${ }^{40}$ Aldosterone stimulates the MAPK pathway and cell-cycle progression in mesangial cells mainly via MR. ${ }^{41}$ Another study demonstrated that aldosterone rapidly induced phosphorylation of JNK and spironolactone abolished aldosterone-induced phosphorylation of $\mathrm{JNK}^{42}$ which is in agreement with our findings. Spironolactone
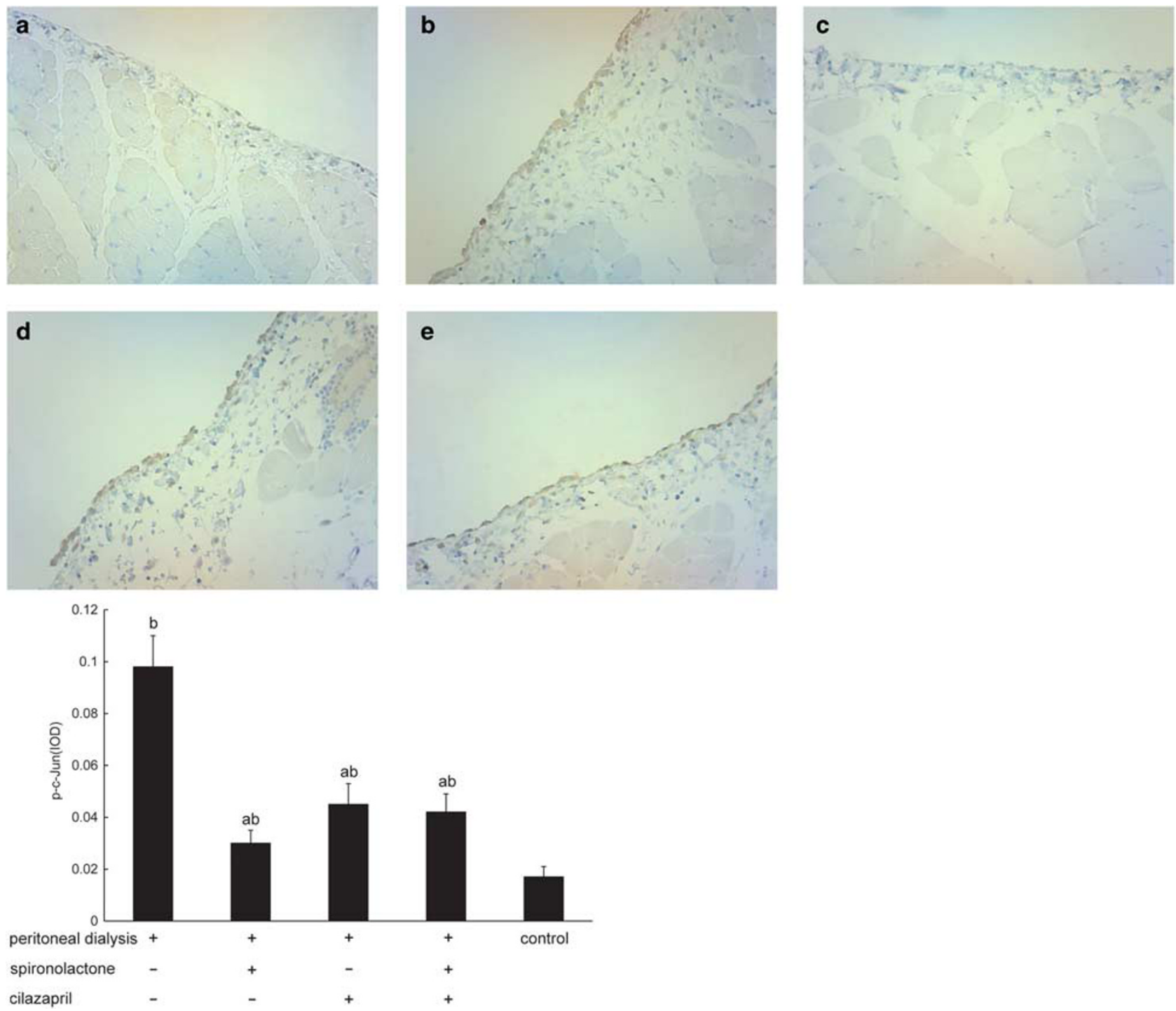

Figure 8 Effect of aldosterone receptor antagonism on p-c-Jun expression in the peritoneum after daily peritoneal dialysis for 30 days. Immunohistochemical staining for p-c-Jun (brown, original magnification $\times 200)(\mathbf{a}-\mathbf{e})$. In the control (a) group, the expression of p-c-Jun was weak; in the peritoneal dialysis (b) group, the expression of p-c-Jun was greater; and in the peritoneal dialysis-spironolactone (c), peritoneal dialysis-cilazapril (d) or peritoneal dialysis-spironolactone-cilazapril (e) groups, spironolactone or cilazapril recover the change. Each histogram represents mean \pm s.e.m. of 10 animals. ${ }^{\mathrm{a}} \mathrm{P}<0.01$ vs peritoneal dialysis (PD) group, ${ }^{\mathrm{b}} \mathrm{P}<0.01$ vs normal control group. 


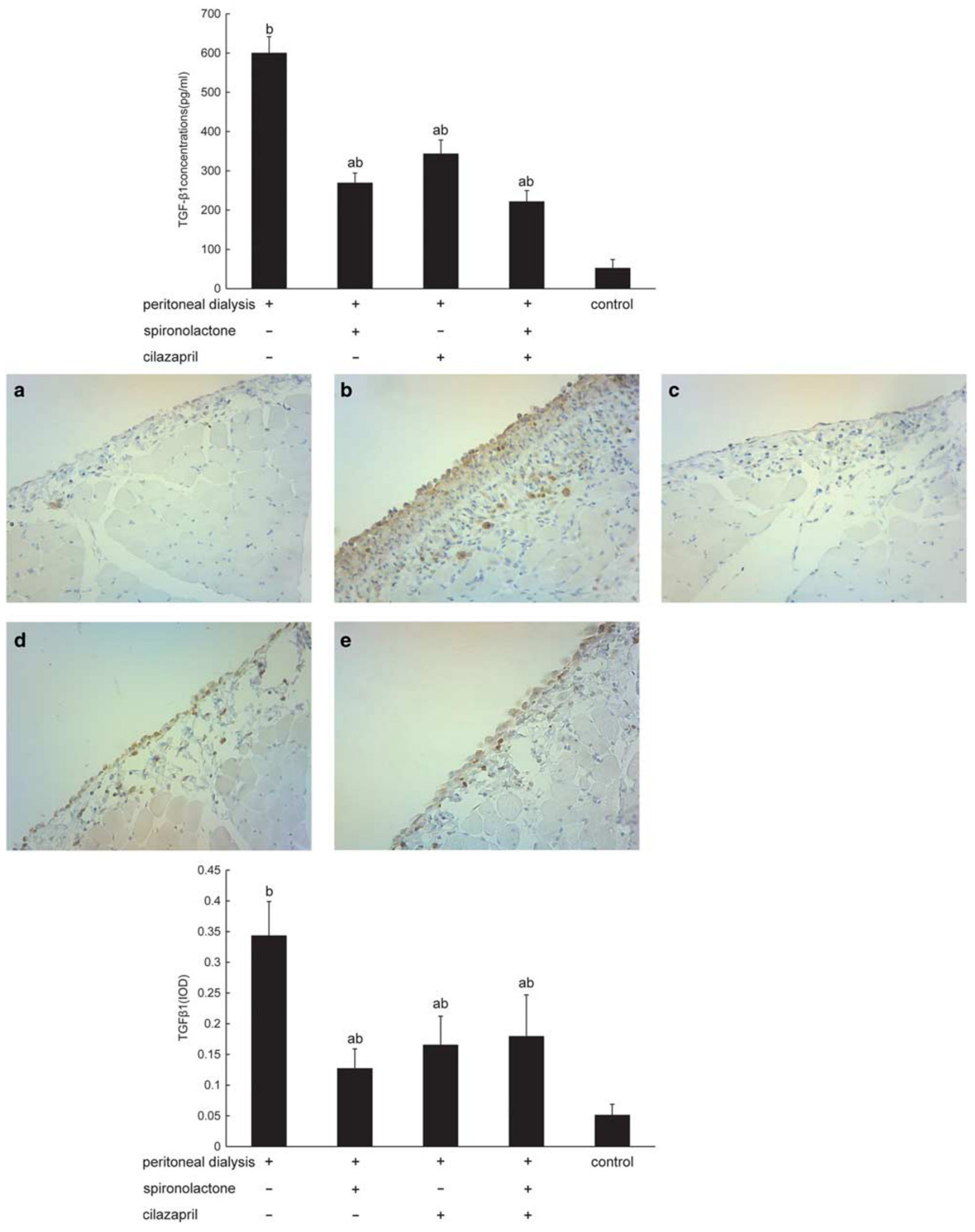


Figure 9 Aldosterone receptor antagonism reduced the levels of TGF- $\beta 1$ in both dialysate and peritoneum. Enzyme-linked immunosorbent assay of TGF- $\beta 1$ in abdominal cavity liquid (1). Immunohistochemical staining for TGF- $\beta 1$ in the abdominal membrane of rats (2) (brown, original magnification $\times 200$ ) (a-e). In the control (a) group, TGF- $\beta 1$ was weak; in the peritoneal dialysis (b) group, the expression of TGF- $\beta 1$ increased; and in the peritoneal dialysis-spironolactone (c), peritoneal dialysis-cilazapril (d) or peritoneal dialysis-spironolactone - cilazapril (e) groups, spironolactone or cilazapril recover the change. Each histogram represents mean \pm s.e.m. of 10 animals. ${ }^{a} P<0.01$ vs peritoneal dialysis (PD) group, ${ }^{b} p<0.01$ vs normal control group.

was shown to downregulate ED1, MCP-1, p-c-Jun, TGF- $\beta 1$ and $\mathrm{FN}$ in the visceral peritoneum.

In our study, aldosterone may have a role in peritoneal fibrosis by combining with MR, stimulating monocyte/ macrophage infiltration and inducing the JNK signaling pathway and TGF- $\beta 1$. Spironolactone may have a protective role in the prevention and treatment of peritoneal fibrosis.

\section{ACKNOWLEDGMENTS}

This work was supported by a grant from the Sino-foreign Collaborating Item of Heilongjiang Province Scientific Committee (WC05C05), Harbin Municipal Science and Technology Innovation Talents funded projects (2006RFLXS027) and the People's Republic of China Ministry of Personnel Fund.

\section{DISCLOSURE/CONFLICT OF INTEREST}

The authors declare no conflict of interest.

1. Williams JD, Craig KJ, Topley $\mathrm{N}$, et al. Morphologic changes in the peritoneal membrane of patients with renal disease. J Am Soc Nephrol 2002;13:470-479.

2. David F, David K. Macrophage cell therapy in renal disease. Semin Nephrol 2010;30:345-353.

3. Vernon MA, Mylonas KJ, Hughes J. Macrophages and renal fibrosis. Semin Nephrol 2010;30:302-317.

4. Margetts PJ, Oh KH, Kolb M. Transforming growth factor-beta: importance in long-term peritoneal membrane changes. Perit Dial Int 2005;25(suppl 3):S15-S17.

5. Lai KN, Lai KB, Lam CW, et al. Changes of cytokine profiles during peritonitis in patients on continuous ambulatory peritoneal dialysis. Am J Kidney Dis 2000;35:644-652.

6. Loureiro J, Aguilera A, Selgas R, et al. Blocking TGF- $\beta 1$ protects the peritoneal membrane from dialysate-induced damage. Am Soc Nephrol 2011;22:1682-1695.

7. Engel ME, McDonnell MA, Law BK, et al. Interdependent Smad and JNK signaling in transforming growth factor-beta-mediated transcription. J Biol Chem 1999:274:37413-37420.

8. Hocevar BA, Prunier C, Howe PH. Disabled-2 (dab2) mediates transforming growth factor beta (TGFbeta)-stimulated fibronectin synthesis through TGFbeta-activated kinase 1 and activation of the JNK pathway. J Biol Chem 2005;280:25920-25927.

9. Alcorn JF, Guala AS, van der Velden J, et al. Jun n-terminal kinase 1 regulates epithelialto-mesenchymal transition induced by TGF-beta1. J Cell Sci 2008:121:1036-1045.

10. Alcorn JF, van der Velden J, Brown AL, et al. c-Jun N-terminal kinase 1 is required for the development of pulmonary fibrosis. Am J Respir Cell Mol Biol 2009;40:422-432.

11. Nakajima T, Yamada T, Setoguchi M. Prolonged inhibition of local angiotensin-converting enzyme after single or repeated treatment with quinapril in spontaneously hypertensive rats. J Cardiovasc Pharmacol 1992;19:102-107.

12. Naftilan AJ, Pratt MJ, Owens GK. Induction of platelet-derived growth factor A chain and c-myc gene expression by Angiotensin II in cultured rat muscle cells. J Clin Invest 1989;83:1419-1424.

13. Gibbons GH, Pratt RE, Dzau VJ. Vascular smooth muscle cell hypertrophy vs hyperplasia: autocrine transforming growth factor- $\beta 1$ expression determines growth response to angiotensin II. J Clin Invest 1992;90:456-461.
14. Lemarié CA, Simeone SM, Nikonova A, et al. Aldosterone-induced activation of signaling pathways requires activity of angiotensin type 1a receptors. Circ Res 2009;105:852-859.

15. Han JS, Choi BS, Yang CW, et al. Aldosterone-induced TGF-beta1 expression is regulated by mitogen-activated protein kinases and activator protein-1 in mesangial cells. J Korean Med Sci 2009;24:S195-S203.

16. Nie J, Dou X, Hao W, et al. Smad7 gene transfer inhibits peritoneal fibrosis. Kidney Int 2007;72:1336-1344.

17. Sach $M$, Loetscher $P$, Burger JA, et al. MCP-1 levels are elevated in peritonitis fluid from CAPD patients due to secretion by peritoneal macrophages. Adv Perit Dial 1995;11:19-23.

18. Sach $M$, Bauermeister $K$, Burger JA, et al. Inverse MCP-1/IL-8 ratio in effluents of CAPD patients with peritonitis and in isolated cultured human peritoneal macrophages. Nephrol Dial Transplant 1997;12:3 15-320.

19. Nakanishi I, Moutabarrik A, Okada N, et al. Interleukin-8 in chronic renal failure and dialysis patients. Nephrol Dial Transplant 1994;9: $1435-1442$.

20. Tekstra J, Visser CE, Tuk CW, et al. Identification of the major chemokines that regulate cell influxes in peritoneal dialysis patients. J Am Soc Nephrol 1996;7:2379-2384.

21. Robson LR, McLouglin MR, Witowski J, et al. Differential regulation of chemokine production in human peritoneal mesothelial cells: INF- $\gamma$ controls neutrophil migration across the mesothelium in vitro and in vivo. J Immunol 2001;167:1028-1038.

22. Fieren MW. The local inflammatory responses to infection of the peritoneal cavity in humans: their regulation by cytokines, macrophages, and other leukocytes. Mediators Inflamm 2012;2012:976241.

23. Bellón $T$, Martínez $V$, Lucendo $B$, et al. Alternative activation of macrophages in human peritoneum: implications for peritoneal fibrosis. Nephrol Dial Transplant 2011;9:2995-3005.

24. Hu W, Jiang $Z$, Zhang $Y$, et al. Characterization of infiltrating macrophages in high glucose-induced peritoneal fibrosis in rats. Mol Med Rep 2012;1:93-99.

25. Weston CR, Davis RJ. The JNK signal transduction pathway. Curr Opin Cell Biol 2007;19:142-149.

26. Flanc RS, Ma FY, Tesch GH, et al. A pathogenic role for JNK signaling in experimental anti-GBM glomerulonephritis. Kidney Int 2007;72: 698-708.

27. Francescato HD, Costa RS, Junior FB, et al. Effect of JNK inhibition on cisplatin-induced renal damage. Nephrol Dial Transplant 2007;22: 2138-2148.

28. De Borst MH, Prakash J, Melenhorst WB, et al. Glomerular and tubular induction of the transcription factor c-Jun in human renal disease. J Pathol 2007;213:219-228.

29. Mori S, Matsuzaki K, Yoshida K, et al. TGF-beta and HGF transmit the signals through JNK-dependent Smad2/3 phosphorylation at the linker regions. Oncogene 2004;23:7416-7429.

30. Verrecchia F, Tacheau C, Wagner EF, et al. A central role for the JNK pathway in mediating the antagonistic activity of pro-inflammatory cytokines against transforming growth factor-beta-driven Smad3/ 4-specific gene expression. J Biol Chem 2003;278:1585-1593.

31. Fuller PJ, Young MJ. Mechanisms of mineralocorticoid action. Hypertension 2005;46:1227-1235.

32. Funder JW. Reconsidering the roles of the mineralocorticoid receptor. Hypertension 2009;53:286-290.

33. Nagase M. Activation of the aldosterone/mineralocorticoid receptor system in chronic kidney disease and metabolic syndrome. Clin Exp Nephrol 2010;14:303-314.

34. Bienvenu LA, Morgan J, Rickard AJ, et al. Macrophage mineralocorticoid receptor signaling plays a key role in aldosteroneindependent cardiac fibrosis. Endocrinology 2012;153:3416-3425. 
35. Brilla CG, Zhou G, Matsubara L, et al. Collagen metabolism in cultured adult rat cardiac fibroblasts: response to angiotensin II and aldosterone. J Mol Cell Cardiol 1994;26:809-820.

36. Zhou G, Kandala JC, Tyagi SC, et al. Effects of angiotensin II and aldosterone on collagen gene expression and protein turnover in cardiac fibroblasts. Mol Cell Biochem 1996;154:171-178.

37. Callera GE, Touyz RM, Tostes RC, et al. Aldosterone activates vascular p38MAP kinase and NADPH oxidase via c-Src. Hypertension 2005;45:773-779.

38. Miric G, Dallemagne C, Endre Z, et al. Reversal of cardiac and renal fibrosis by pirfenidone and spironolactone in streptozotocin-diabetic rats. Br J Pharmacol 2001;133:687-694.
39. $\mathrm{Ha} \mathrm{H}$, Lee HB. Effect of high glucose on peritoneal mesothelial cell biology. Perit Dial Int 2000;20(Suppl 2):S15-S18.

40. Eesoy R, Celik A, Yilmaz $\mathrm{O}$, et al. The effects of irbesartan and spironolactone in prevention of peritoneal fibrosis in rats. Perit Dial Int 2007:27:424-431.

41. Terada $\mathrm{Y}$, Kobayashi $\mathrm{T}$, Kuwana $\mathrm{H}$, et al. Aldosterone stimulates proliferation of mesangial cells by activating mitogen-activated protein kinase 1/2, Cyclin D1, and CyclinA. J Am Soc Nephrol 2005;16:2296-2305.

42. Han J-S, Choi B-S, Yang C-W, et al. Aldosterone-induced TGF- $\beta 1$ expression is regulated by mitogen-activated protein kinases and activator protein-1 in mesangial cells. J Korean Med Sci 2009; 24(Suppl I):S195-S203. 